\title{
CST Complex Subunit STN1
}

National Cancer Institute

\section{Source}

National Cancer Institute. CST Complex Subunit STN1. NCI Thesaurus. Code C131361.

CST complex subunit STN1 (368 aa, $42 \mathrm{kDa}$ ) is encoded by the human ST N1 gene. This protein is involved in DNA binding, telomere homeostasis and DNA replication. 